\title{
Linearly Unbiased Estimation Combined with JC Method for the Carbonation Contamination of Some Concrete Bridges in Taipei
}

\author{
Ming-Te Liang \\ Professor, Department of Harbor and River Engineering, National Taiwan Ocean University, Keelung 20224, Taiwan. \\ Guo-Fan Zhao \\ Professor, Department of Civil Engineering, Dalian University of Technology, Dalian 116024, China. \\ Yen-Sheng Liao \\ Graduate Student, Department of Harbor and River Engineering, National Taiwan Ocean University, Keelung 20224, \\ Taiwan. \\ Chih-Hsin Liang \\ Postgraduate Student, Institute of Material Engineering, National Taiwan Ocean University, Keelung 20224, Taiwan.
}

Follow this and additional works at: https://jmstt.ntou.edu.tw/journal

Part of the Civil and Environmental Engineering Commons

\section{Recommended Citation}

Liang, Ming-Te; Zhao, Guo-Fan; Liao, Yen-Sheng; and Liang, Chih-Hsin (2000) "Linearly Unbiased Estimation Combined with JC Method for the Carbonation Contamination of Some Concrete Bridges in Taipei," Journal of Marine Science and Technology. Vol. 8: Iss. 2, Article 3.

DOI: $10.51400 / 2709-6998.2457$

Available at: https://jmstt.ntou.edu.tw/journal/vol8/iss2/3

This Research Article is brought to you for free and open access by Journal of Marine Science and Technology. It has been accepted for inclusion in Journal of Marine Science and Technology by an authorized editor of Journal of Marine Science and Technology. 


\title{
LINEARLY UNBIASED ESTIMATION COMBINED WITH JC METHOD FOR THE CARBONATION CONTAMINATION OF SOME CONCRETE BRIDGES IN TAIPEI
}

\author{
Ming-Te-Liang*, Guo-Fan Zhao**, Yen-Sheng Liao*** and Chih-Hsin Liang****
}

Keywords: Carbonation depth, Cover thickness, Reliability index, Failure Probability.

\section{ABSTRACT}

The main purpose of this investigation was to study the durability evaluations of existing concrete bridges due to carbonation contamination. The linearly unbiased estimation method associated with the JC method developed by the Joint Committee on Structural Safety was adopted to predict the mean value and standard deviation of the normal distribution for the carbonation depths and cover thickness of concrete bridges. The reliability index $(\beta)$ and failure probability $\left(P_{f}\right)$ of concrete bridges were also evaluated. Since the linearly unbiased estimation method is very suitable for analyzing a small number of specimens obtained from practical engineering problems, the unknown parameters can be conveniently and actually determined. In order to verify this proposed method, ten concrete bridges in Taipei were used to predict the mean value, standard deviation, reliability index and failure probability. In this paper, the results of this investigation indicate that both the Beei-men viaduct ( $\beta$ $=0.23)$ and the Jzyh-chyang bridge $(\beta=0.39)$ require extensive repair. Both the Ay-gwo west road viaduct $(\beta=0.92)$ and the Shiyuan bridge $(\beta=0.88)$ require relatively light repairs. The other bridges $(\beta=1 \sim 2.0)$ are safe and serviceable. The linearly unbiased estimation combined with JC method is useful to evaluate the durability of existing concrete bridges with carbonation contamination.

\section{INTRODUCTION}

The reinforced steel bars embedded in concrete are protected from corrosion by a thin oxide film that forms on their surface due to the highly alkaline, with $\mathrm{pH}$

Paper Received Sep. 1, 2000. Author for Correspondence: M. T. Liang. *Professor, Department of Harbor and River Engineering, National Taiwan Ocean University, Keelung 20224, Taiwan.

**Professor, Department of Civil Engineering, Dalian University of Technology, Dalian 116024, China.

***Graduate Student, Department of Harbor and River Engineering, National Taiwan Ocean University, Keelung 20224, Taiwan.

****Postgraduate Student, Institute of Material Engineering, National Taiwan Ocean University, Keelung 20224, Taiwan. values above 12.5 , environment of the surrounding concrete. This alkalinity occurs calcium hydroxide $(\mathrm{Ca}$ $\left.(\mathrm{OH})_{2}\right)$ ) produced during the reaction between water and the constituents of cement which occurs the hardening and development of strength of cement and concrete. Carbon dioxide $\left(\mathrm{CO}_{2}\right)$ in air penetrates into concrete and reduces the $\mathrm{pH}$ value less than 9 , that can result in the corrosion of embedded reinforcing steel bars which cause concrete to spall or split. This process is called carbonation that is principally a diffusion phenomenon and the rate of penetration of $\mathrm{CO}_{2}$ depends mainly on concrete quality and exposure conditions.

The existing concrete bridges in Taipei were evaluated for corrosion contamination in order to select the most effective repair methods. A detailed investigation was required to determine the extent and cause of deterioration. Corrosion in steel reinforcement is a major cause of concrete deterioration in Taipei. It has been observed that significant corrosion-induced deterioration in Taipei occurs with 10 to 15 years of construction. Corrosion of the existing concrete bridges is at first caused by the presence of carbonation. The aggressive environment in Taipei is characterized high temperature and humidity cycles, and high levels of carbon dioxide.

As the various factors which influence concrete carbonation are uncertain, the actual carbonation depths of concrete structures are also uncertain. The carbonation processes of concrete structures are very complex. At present there is little statistical data on the factors which influence concrete carbonation. Thus, it is still difficult to use the existing calculation formulas to determine the statistical rules for concrete carbonation. However, in practical engineering problems, it is sometimes urgent to perform a probability estimation for concrete carbonation. A simple and practical method is to directly carry out statistical analysis for the concrete carbonation. The traditionally statistical methods re- 
quire numerous specimens. However, in actual practice, few specimens obtained from field tests are used to determine the extent of carbonation.

Freudenthal [1] used the principle of constant reliability over the domain of load influence coefficients to study the structural reliability. Cornell [2], Lind [3] and Ravindra et al. [4] developed the theory of codified structural design to serve as an efficient way to encode experience. Ang and Amin [5] proposed an approach which explicitly separates the elements of risk (variables with known probability measure) from the elements of uncertainty (variables with unknown probability measure). This format can be completely reconciled with the partial safety factor format derived by appropriate identification of terms. Lind [6] demonstrated how partial safety factors in a design code can be selected to balance safety and economy. Paloheimo and Hannus [7] derived a deterministic design equation in which all random variables are substituted by appropriate design values. A design value is a function of the mean value and standard deviation of the corresponding random variable; the reliability factor, which is determined by the acquired level of safety; and the sensitivity factor, which expresses the sensitivity of the structure to the individual random variable. Stewart and Rosowsky $[8,9]$ developed a structural deterioration reliability model to calculate probabilities of structural failure for a typical reinforced concrete continuous slab bridge. Until now, however, no studies have attempted to predict the durability of existing $\mathrm{RC}$ bridges without employing linearly unbiased estimation combined with the JC method. This is a notable shortcoming, because the use of reliability analysis in previous studies may be needed a lot of specimens.

This paper is focused on the durability evaluation of concrete bridges due to carbonation contamination. In order to investigate this subject, the research significance must first be pointed out. Second, the linearly unbiased estimation of parameter method is described. Third, the JC method [7] is introduced. Fourth, a testing technique for specimens which were extracted from ten different concrete bridges in Taipei is described. Fifth, the results and discussion are provided. Finally, concluding remarks are drawn.

\section{RESEARCH SIGNIFICANCE}

The reliability index or the failure probability can be used to predict the state of contamination in structures. The carbonation contamination of ten concrete bridges in Taipei were evaluated using the reliability index. The decision as to whether a given bridge requires repair can be made based on the estimated reliability index.

\section{LINEARLY UNBIASED ESTIMATION OF PARAMETER}

The unknown parameters of a small number of specimens with a small account of engineering problem data can be conveniently and actually predicted using linearly unbiased estimation method. Suppose that there exists a set of specimen sequence $\left(x_{1}, x_{2}, \ldots, x_{n}\right)$. Consider an estimated value of linear function

$$
x_{p}=\lambda+\alpha y_{p}
$$

where $\lambda$ is position parameter and $\alpha$ is scale parameter.

The linear function with specimen sequence $\left(x_{1}\right.$, $\left.x_{2}, \ldots, x_{n}\right)$ is defined as

$$
L=\sum_{i=1}^{n} w_{i} x_{i}
$$

where $w_{i}$ is the weighting value and is expressed as

$$
w_{i}=a_{i}+b_{i} y_{p}
$$

where $a_{i}$ and $b_{i}$ are coefficient functions.

The limit property of $w_{i}$ is $\sum_{i=1}^{n} w_{i}=1$.

The expectation of linear function $L$ can be expressed in terms of

$$
E(L)=\sum_{i=1}^{n} w_{i} E\left(x_{i}\right)=x_{p}
$$

The linearly unbiased estimation method means that the sought variance of $L$ is the minimum weight $w_{i}$. If the value of specimen $x_{i}$ coincides with expectation $E$ $\left(x_{i}\right)$, then the variance vanishes. However, if the value of specimen $x_{i}$ does not coincide with expectation $E\left(x_{i}\right)$, then we must determine $w_{i}$ such that

$x_{p}=E(L) \approx \sum_{i=1}^{n} w_{i} x_{i}=L$

The variance of $L$ is

$\sigma_{L}^{2}=E[L-E(L)]^{2}=E\left(L^{2}\right)-[E(L)]^{2}$

Because

$\sum_{i=1}^{n} w_{i}=1$

$\sum_{i=1}^{n} w_{i} E\left(y_{i}\right)=y_{p}$

$L=\sum_{i=1}^{n} w_{i} x_{i}=\sum_{i=1}^{n} w_{i}\left(\lambda+\alpha y_{i}\right)$

The substitution of Eqs. (7), (8) and (9) into Eq. (6) yields 


$$
\sigma_{L}^{2}=\alpha^{2} \sum_{i=1}^{n} \sum_{j=1}^{n}\left[E\left(y_{i} y_{j}\right)-E\left(y_{i}\right) E\left(y_{j}\right)\right] w_{i} w_{j}
$$

Introducing the Lagrangian coefficients $\lambda_{1}$ and $\lambda_{2}$ which are to be determined, and using the constrain conditions, i.e. Eqs. (8) and (9), we can construct the function

$$
\begin{aligned}
I & =\sum_{i=1}^{n} \sum_{j=1}^{n}\left[E\left(y_{i} y_{j}\right)-E\left(y_{i}\right) E\left(y_{j}\right)\right] w_{i} w_{j} \\
& +\lambda_{1}\left(\sum_{i=1}^{n} w_{i}-1\right)+\lambda_{2}\left[\sum_{i=1}^{n} w_{i} E\left(y_{i}\right)-y_{p}\right]
\end{aligned}
$$

In order to find the $w_{i}$ such that the variance, $\sigma_{L}^{2}$, is minimum, it is required that

$$
\frac{\partial I}{\partial w_{i}}=0 ; \quad(i=1,2, \ldots, n)
$$

When $w_{i}$ is determined using the above method, we can obtain a system of linear equations. After rearrangement of Eq. (5)

$$
\begin{aligned}
x_{p} & =\lambda+\alpha y_{p}=\sum_{i=1}^{n}\left(a_{i}+b_{i} y_{p}\right) x_{i} \\
& =\sum_{i=1}^{n} a_{i} x_{i}+\left(\sum_{i=1}^{n} b_{i} x_{i}\right) y_{p}
\end{aligned}
$$

we get

$$
\begin{aligned}
& \lambda=\sum_{i=1}^{n} a_{i} x_{i} \\
& \alpha=\sum_{i=1}^{n} b_{i} x_{i}
\end{aligned}
$$

where $a_{i}$ and $b_{i}$ are the functions of $E\left(y_{i}\right), E\left(y_{i}^{2}\right)$ and $E\left(y_{i} y_{j}\right)$ in the system of linear equations mentioned above. For calculating the values of $E\left(y_{i}\right), E\left(y_{i}{ }^{2}\right)$ and $E\left(y_{i} y_{j}\right)$, we adopted the following method (see Fig. 1). If the value of $y_{i}$ is the statistical value according to the right $i$-th orders, then the 1 st to $(i-1)$-th data locates the A region, as shown in Fig. 1 and the $(i+1)$-th to $n$-th data set in $\mathrm{B}$ region. Thus, the probability density function of the -th value of $y_{i}$ is

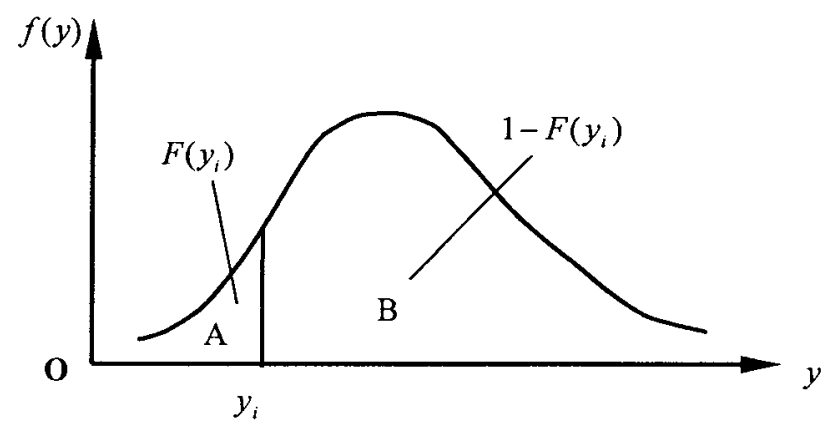

Fig. 1. Schematic diagram for finding $E\left(y_{i}\right)$.

$$
P_{i}(y)=\frac{n !}{(i-1) !(n-1) !}[F(y)]^{i-1}[1-F(y)]^{n-i} f(y)
$$

The corresponding expected values of $y_{i}$ and $y_{i}^{2}$ are, respectively, expressed as

$$
\begin{aligned}
& E\left(y_{i}\right)=\int_{-\infty}^{+\infty} y P_{i}(y) d y \\
& E\left(y_{i}^{2}\right)=\int_{-\infty}^{+\infty} y^{2} P_{i}(y) d y
\end{aligned}
$$

Assume that the values of the $i$-th and $j$-th variables of $y_{i}$ and $y_{j}$ are $u$ and $v$, respectively. In a similar manner, using Fig. 2, the probability density function of the expected value of $y_{i} y_{j}$ can be calculated. The 1 st to $(i-1)$-th, $(i+1)$-th to $(j-1)$-th, and $(j+1)$-th to $n$-th data locate $\mathrm{A}, \mathrm{B}$ and $\mathrm{C}$ regions, as illustrated in Fig. 2, respectively. Therefore, the probability density function of $u$ and $v$ is

$$
\begin{aligned}
P_{i j}(u, v)= & \frac{n !}{(i-1) !(j-i-1) !(n-j) !}[F(u)]^{i-1} \\
& {[F(v)-F(u)]^{j-i-1}[1-F(v)]^{n-j} f(u) f(v) }
\end{aligned}
$$

The corresponding expected value of $u$ and $v$ is

$$
E\left(y_{i} y_{i}\right)=\int_{-\infty}^{+\infty} \int_{-\infty}^{+\infty} u v P_{i j}(u, v) d u d v ;(u<v)
$$

When both $f(\bullet)$ and $F(\bullet)$ are given, the representative equations $E\left(y_{i}\right), E\left(y_{i}^{2}\right)$ and $E\left(y_{i} y_{j}\right)$ can be calculated from Eqs. (17), (18) and (20), respectively.

Zhao (1996) pointed out that the concrete carbonation corrosion usually obeys the standard normal distribution

$$
\begin{aligned}
& f(x)=\frac{1}{\sqrt{2 \pi} \sigma} \exp \left[-\frac{(x-\mu)^{2}}{2 \sigma^{2}}\right] \\
& F(x)=\Phi(x)=\int_{-\infty}^{x} f(t) d t
\end{aligned}
$$

where $f(x)$ and $F(x)$ are the probability density function

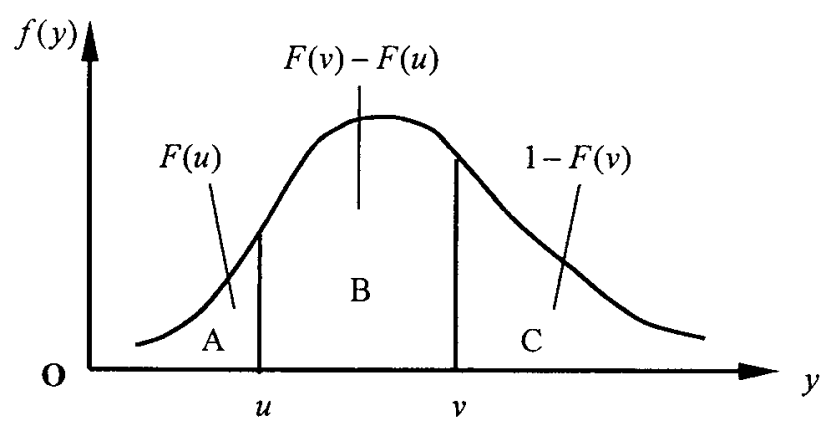

Fig. 2. Schematic diagram for finding $E\left(y_{i} y_{j}\right)$. 
and distribution function, respectively. $\Phi(x)$ is the standard normal distribution function. The mean value $\mu_{x}$ and standard deviation $\sigma_{x}$ of the concrete carbonation depth can be, respectively, estimated in terms of

$$
\begin{aligned}
& \mu_{x}=\sum_{i=1}^{n} a_{i} x_{i}=\frac{1}{n} \sum_{i=1}^{n} x_{i} \\
& \sigma_{x}=\sum_{i=1}^{n} b_{i} x_{i}
\end{aligned}
$$

where the coefficient $b_{i}$ can be determined from Table 1 , and the permutation order of specimen is $x_{1} \geq x_{2} \geq \ldots \geq$ $x_{n}$.

\section{JC METHOD}

Paloheimo and Hannus [7] proposed a method of checking computations. The feature of this method is considered an abnormal random variable. Under the computational data conditions, increased by only a few, the reliability index, $\beta$, could actually perform the approximate calculation and determine the design value by checking which computation point satisfies the limit state equation. It is very convenient to calculate each item coefficient of the standard value given by the specification. It is also easy to produce the expressed design formula with the usual multiple coefficient for the designer.

In this study, the linearly limit state equation, with two normal random variables, was considered to eluci- date the reliability index, $\beta$, and the concept of checking designed the computation point.

The limit state equation with two random variables can be expressed as

$$
Z=g(R, S)=R-S=0
$$

where $R$ is the structural resistance, $S$ is the loading effect of the structural surface, and $Z=g(R, S)$ is a function. It is pointed out that $R$ and $S$ are mutually independent and are obeyed the standard normal distribution. Fig. 3 indicates the limit state equation and designed computation check point for two normal random variables. In the case of the $O S R$ coordinate, the limit state equation is a straight line which have an inclined angle $45^{\circ}$ with a horizontal axis. Let $R$ and $S$ be divided by the standard deviations $\sigma_{R}$ and $\sigma_{S}$, respectively. The coordinates $S^{\prime}=\frac{S}{\sigma_{S}}$ and $R^{\prime}=\frac{R}{\sigma_{R}}$ are formed as shown in Fig. 3. When $\sigma_{S} \neq \sigma_{R}$, the inclined angle of the straight line $R^{\prime}=\left(\sigma_{R} / \sigma_{S}\right) S^{\prime}$ of the limit state equation in the coordinate $O^{\prime} S^{\prime} R^{\prime}$ is not $45^{\circ}$ while $\tan ^{-1}$ $\left(\sigma_{R} / \sigma_{S}\right)$. If the coordinate $O^{\prime} S^{\prime} R^{\prime}$ is translated from origin $O^{\prime}(0,0)$ to $\bar{O}\left(\frac{\mu_{S}}{\sigma_{S}}, \frac{\mu_{R}}{\sigma_{R}}\right)$ as depicted in Fig. 3, then the new coordinate $\bar{O} \bar{S} \bar{R}$ is obtained and is expressed by

$$
\begin{aligned}
& \bar{S}=\frac{S}{\sigma_{S}}-\frac{\mu_{S}}{\sigma_{S}}=\frac{S-\mu_{S}}{\sigma_{S}} \\
& \bar{R}=\frac{R-\mu_{R}}{\sigma_{R}}
\end{aligned}
$$

\begin{tabular}{|c|c|c|c|c|c|c|c|c|c|c|c|c|c|c|c|c|c|c|c|c|}
\hline $\mathrm{n}$ & $b_{1}$ & $b_{2}$ & $b_{3}$ & $b_{4}$ & $b_{5}$ & $b_{6}$ & $b_{7}$ & $b_{8}$ & $b_{9}$ & $b_{10}$ & $b_{11}$ & $b_{12}$ & $b_{13}$ & $b_{14}$ & $b_{15}$ & $b_{16}$ & $b_{17}$ & $\mathrm{~b}_{18}$ & $\mathrm{~b}_{19}$ & $b_{20}$ \\
\hline 2 & -0.886 & 0.88 & & & & & & & & & & & & & & & & & & \\
\hline 3 & -0.591 & 0.000 & 0.591 & & & & & & & & & & & & & & & & & \\
\hline 4 & -4.454 & -0.110 & 0.110 & 4.454 & & & & & & & & & & & & & & & & \\
\hline 5 & -0.372 & -0.135 & 0.000 & 0.135 & 0.372 & & & & & & & & & & & & & & & \\
\hline 6 & -0.318 & -0.139 & -0.043 & 0.043 & 0.139 & 0.318 & & & & & & & & & & & & & & \\
\hline 7 & -0.278 & -0.135 & -0.062 & 0.000 & 0.062 & 0.135 & 0.278 & & & & & & & & & & & & & \\
\hline 8 & -0.248 & -0.129 & -0.071 & -0.023 & 0.023 & 0.071 & 0.129 & 0.248 & & & & & & & & & & & & \\
\hline 9 & -0.224 & -0.123 & -0.075 & -0.036 & 0.000 & 0.036 & 0.075 & 0.123 & 0.224 & & & & & & & & & & & \\
\hline 10 & -0.204 & -0.117 & -0.076 & -0.044 & -0.014 & 0.014 & 0.044 & 0.076 & 0.117 & 0.204 & & & & & & & & & & \\
\hline 11 & -0.188 & -0.111 & -0.076 & -0.048 & -0.024 & 0.000 & 0.024 & 0.048 & 0.076 & 0.111 & 0.188 & & & & & & & & & \\
\hline 12 & -0.175 & -0.106 & -0.075 & -0.051 & -0.029 & -0.010 & 0.010 & 0.029 & 0.051 & 0.075 & 0.106 & 0.175 & & & & & & & & \\
\hline 13 & -0.163 & -0.101 & -0.074 & -0.052 & -0.033 & -0.017 & 0.000 & 0.017 & 0.033 & 0.052 & 0.074 & 0.101 & 0.163 & & & & & & & \\
\hline 14 & -0.153 & -0.097 & -0.072 & -0.052 & -0.036 & -0.022 & -0.006 & 0.006 & 0.022 & 0.036 & 0.052 & 0.072 & 0.097 & 0.153 & & & & & & \\
\hline 15 & -0.144 & -0.093 & -0.070 & -0.053 & -0.037 & -0.026 & -0.011 & 0.000 & 0.011 & 0.026 & 0.037 & 0.053 & 0.070 & 0.093 & 0.144 & & & & & \\
\hline 16 & -0.137 & -0.089 & -0.068 & -0.053 & -0.038 & -0.028 & -0.016 & -0.005 & 0.005 & 0.016 & 0.028 & 0.038 & 0.053 & 0.068 & 0.089 & 0.137 & & & & \\
\hline 17 & -0.130 & -0.086 & -0.066 & -0.052 & -0.040 & -0.029 & -0.019 & -0.009 & 0.000 & 0.009 & 0.019 & 0.029 & 0.040 & -0.052 & 0.066 & 0.086 & 0.130 & & & \\
\hline 18 & -0.124 & -0.082 & -0.065 & -0.050 & -0.041 & -0.030 & -0.020 & -0.014 & -0.004 & 0.004 & 0.014 & 0.020 & 0.030 & 0.041 & 0.050 & 0.065 & 0.082 & $0.124-$ & & \\
\hline 19 & -0.118 & -0.079 & -0.063 & -0.051 & -0.039 & -0.032 & -0.024 & -0.014 & -0.008 & 0.000 & 0.008 & 0.014 & 0.024 & 0.032 & 0.039 & 0.051 & 0.063 & 0.079 & 0.118 & \\
\hline 20 & -0.113 & -0.076 & -0.061 & -0.049 & -0.041 & -0.032 & -0.025 & -0.017 & -0.010 & -0.003 & 0.003 & 0.010 & 0.017 & 0.025 & 0.032 & 0.041 & 0.049 & 0.061 & 0.076 & 0.113 \\
\hline
\end{tabular}

Table 1. Coefficient $b_{i}$ of linearly unbiased estimation in standard normal distribution 


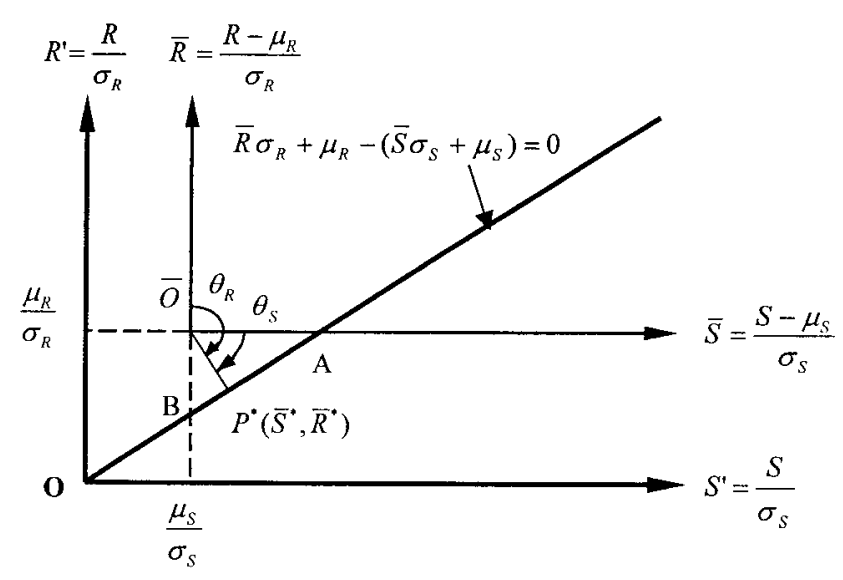

Fig. 3. Limit state equation and designed checking computation point of two normal random variables.

The coordinate transform stated above is in fact the normal distribution $N\left(\mu_{i}, \sigma_{i}\right)$ standardized as $N(0,1)$.

The relationship between the original coordinate $O S R$ and the new coordinate $\bar{O} \bar{S} \bar{R}$ is

$$
\begin{aligned}
& S=\bar{S} \sigma_{S}+\mu_{S} \\
& R=\bar{R} \sigma_{R}+\mu_{R}
\end{aligned}
$$

Substituting Eq. (27) into Eq. (25), we get

$$
\bar{R} \sigma_{R}-\bar{S} \sigma_{S}+\mu_{R}-\mu_{S}=0
$$

Equation (28) divided by $-\sqrt{{\sigma_{R}}^{2}+\sigma_{S}^{2}}$ and compared with the straight line of the standard type normal expression in analytic geometry

$$
\bar{S} \cos \theta_{R}+\bar{R} \cos \theta_{R}-\beta=0
$$

we obtain

$$
\begin{aligned}
& \cos \theta_{S}=\frac{\sigma_{S}}{\sqrt{{\sigma_{R}}^{2}+{\sigma_{S}}^{2}}} \\
& \cos \theta_{R}=\frac{-\sigma_{R}}{\sqrt{{\sigma_{R}}^{2}+\sigma_{S}^{2}}} \\
& \beta=\frac{\mu_{R}-\mu_{S}}{\sqrt{{\sigma_{R}}^{2}+\sigma_{S}{ }^{2}}}
\end{aligned}
$$

where $\beta$ is the distance $\overline{\bar{O} P^{*}}$, in which $P^{*}$ is perpendicular toe, from the original point $\bar{O}$ in coordinate $\bar{O} \bar{S} \bar{R}$ to the straight line of limit state equation, $\cos \theta_{S}$ and $\cos \theta_{R}$ are the directional cosine of normal line $\bar{O} P^{*}$ to coordinate. The $\beta$ in Eq. (32) is a reliability index. Hence, the reliability index, $\beta$, is the shortest distance from the original point $\bar{O}$ of the standard normal coordinate $\bar{O} \bar{S} \bar{R}$ to the straight line of the limit state equation. This is the geometrical illustration of $\beta$. In the method for checking the computation point, the calculation of $\beta$ is equivalent to finding the length of $\overline{O P} P^{*} . \quad P^{*}$ is the point on the straight line of the limit state equation. It is called the design computation check point. From Fig. 3, the coordinates $\bar{S}^{*}$ and $\bar{R}^{*}$ of $P^{*}$ are, respectively, stated as

$$
\begin{aligned}
& \bar{S}^{*}=\overline{\bar{O} P^{*}} \cos \theta_{S}=\beta \cos \theta_{S} \\
& \bar{R}^{*}=\overline{\bar{O} P^{*}} \cos \theta_{R}=\beta \cos \theta_{R}
\end{aligned}
$$

Obviously, the directional cosine of $\overline{\overline{O P} P^{*}}$ has the following relationship

$$
\cos ^{2} \theta_{R}+\cos ^{2} \theta_{S}=\frac{\sigma_{R}^{2}}{\sigma_{R}^{2}+\sigma_{S}^{2}}+\frac{\sigma_{S}^{2}}{\sigma_{R}^{2}+\sigma_{S}^{2}}=1
$$

According to Eq. (27), the designed checking computation point $P^{*}\left(\bar{S}^{*}, \bar{R}^{*}\right)$ in the coordinate $\bar{O} \bar{S} \bar{R}$ is expressed in the coordinate $O S R$ as

$$
\begin{aligned}
& S^{*}=\bar{S}^{*} \sigma_{S}+\mu_{S}=\beta \cos \theta_{S} \sigma_{S}+\mu_{S} \\
& R^{*}=\beta \cos \theta_{R} \sigma_{R}+\mu_{R}
\end{aligned}
$$

The limit state equation $(R-S)=0$ in the coordinate $O S R$ is described early. Therefore, the coordinate $P^{*}\left(S^{*}, R^{*}\right)$ on the straight line of the limit state equation should be satisfied

$$
R^{*}-S^{*}=0
$$

If $\mu_{R}, \mu_{S}, \sigma_{R}$ and $\sigma_{S}$ are given, then the reliability index $\beta$ and both $R^{*}$ and $S^{*}$ of the value of the design computation check point can be found from Eqs. (32), (36) and (37). Thus, the corresponding failure probability $P_{f}=\Phi(-\beta)$ is also determined. If both the objective reliability index, $\beta_{T}$, (or the failure probability, $P_{f}$ ) and $\mu_{S}, \sigma_{R}$ and $\sigma_{S}$ are known, then $\mu_{R}$ can be obtained and carried out through the cross-section area design.

The criteria for comprehensive test about reliability index in this paper is suggested as follows: If $0<\beta$ $<0.5$, bridge requires extensive repair. If $0.5<\beta<1.0$, bridge requires relatively light repair. If $\beta \geq 1.0$, bridge is safe and serviceable.

\section{TESTING TECHNIQUES}

Cores were extracted from ten different bridges in Taipei. For each bridge, numerous cores of $55 \mathrm{~mm}$ diameter with $110 \mathrm{~mm}$ height were taken. These specimens were tested carbonation depth. 
Cores were taken from exposed reinforced concrete members of bridges. The majority of the bridges considered were concrete bridges. Cores were extracted and tested according to ASTM-C-39 [10]. All cores were extracted from the girders, diaphram, capbeam, parapets, decks, piers, abutments, and ramps. The cores were cut using a rotary steel cutting machine with diamond bits.

The density and compressive strength are not considered in this paper. The carbonation depth was as- sessed by splitting the concrete cores and spraying the split specimens uniformly with phenolphthalein $\mathrm{pH}$ indicator (a solution of $1 \%$ phenolphthalein $\left(\mathrm{C}_{20} \mathrm{H}_{14} \mathrm{O}_{4}\right)$ in $70 \%$ ethyl alcohol $\left(\mathrm{C}_{2} \mathrm{H}_{5} \mathrm{OH}\right)$ ) (Dhir, et al. [11]), Papadakis, et al. [12], Loo, et al. [13], Al-Khaiat and Haque [14]). The depth of carbonation was measured with a steel ruler to the nearest $1 \mathrm{~mm}$. Several measurements were taken on given specimens. The average cover thickness of each member of the ten bridges were also obtained and are shown in Table 2 to 11 .

Table 2. Unbiased estimation of concrete carbonation depth for the Huey-tong bridge in Taipei*

\begin{tabular}{cccccccc}
\hline $\begin{array}{c}\text { Order } \\
i\end{array}$ & $\begin{array}{c}\text { Member } \\
\text { Classification }\end{array}$ & $\begin{array}{c}\text { Cover } \\
\text { Thickness } \\
d(\mathrm{~mm})\end{array}$ & $\begin{array}{c}\text { Carbonation } \\
\text { Depth } \\
x_{i}(\mathrm{~mm})\end{array}$ & $a_{i}$ & $b_{i}$ & $a_{i} x_{i}$ & $b_{i} x_{i}$ \\
\hline 1 & North deck & 30 & 0 & 0.17 & -0.318 & 0.00 & 0.00 \\
2 & Arch bridge(south) & 30 & 8 & 0.17 & -0.139 & 1.36 & -1.112 \\
3 & S11 deck & 30 & 13 & 0.17 & -0.043 & 2.21 & -0.559 \\
4 & D11 diaphram & 30 & 15.1 & 0.17 & 0.043 & 2.57 & 0.649 \\
5 & West abutment & 30 & 19.5 & 0.17 & 0.139 & 3.32 & 2.711 \\
$\mathrm{n}=6$ & East abutment & 30 & 21 & 0.17 & 0.318 & 3.57 & 6.678 \\
\hline
\end{tabular}

*: The actual service life of the structural members, $t_{0}=49$ years; the normal distribution of cover thickness, $\mathrm{N}(30,0)$; $a_{i}=\left[\frac{1}{n} \sum_{i=1}^{n} x_{i}\right] /\left[\sum_{i=1}^{n} x_{i}\right]=0.17 ; \mu_{x}=\sum_{i=1}^{n} a_{i} x_{i}=13.03 ; \sigma_{x}=\sum_{i=1}^{n} b_{i} x_{i}=8.367 ; \quad \beta=\frac{\mu_{d}-\mu_{x}}{\sqrt{\sigma_{d}^{2}+\sigma_{x}^{2}}}=\frac{30-13.03}{\sqrt{0^{2}+(8.367)^{2}}}=\frac{16.97}{8.367}=$ 2.03; $P_{f}=\Phi(-\beta)=\Phi(-2.03)=0.02118$

Table 3. Unbiased estimation of concrete carbonation depth for the Beei-men viaduct in Taipei*

\begin{tabular}{|c|c|c|c|c|c|c|c|}
\hline $\begin{array}{c}\text { Order } \\
i\end{array}$ & $\begin{array}{c}\text { Member } \\
\text { Classification }\end{array}$ & $\begin{array}{c}\text { Cover } \\
\text { Thickness } \\
d(\mathrm{~mm})\end{array}$ & $\begin{array}{c}\text { Carbonation } \\
\text { Depth } \\
x_{i}(\mathrm{~mm})\end{array}$ & $a_{i}$ & $b_{i}$ & $a_{i} x_{i}$ & $b_{i} x_{i}$ \\
\hline 1 & pier (left, back) & 25 & 1.8 & 0.05 & -0.113 & 0.09 & -0.203 \\
\hline 2 & A10 pier (back) & 25 & 2.0 & 0.05 & -0.076 & 0.10 & -0.015 \\
\hline 3 & A5 capbeam (back) & 20 & 3.6 & 0.05 & -0.061 & 0.18 & -0.220 \\
\hline 4 & G4 girder (left) (C5 C6) & 20 & 4.4 & 0.05 & -0.049 & 0.22 & -0.216 \\
\hline 5 & A15 pier & 25 & 5.1 & 0.05 & -0.041 & 0.26 & -0.209 \\
\hline 6 & C7 pier (back) & 25 & 5.5 & 0.05 & -0.032 & 0.28 & -0.176 \\
\hline 7 & A13 pier & 25 & 6.8 & 0.05 & -0.025 & 0.33 & -0.170 \\
\hline 8 & G5 girder (left) L & 20 & 7.4 & 0.05 & -0.017 & 0.37 & -0.126 \\
\hline 9 & A1 pier (right, back) & 25 & 7.8 & 0.05 & -0.010 & 0.39 & -0.078 \\
\hline 10 & A8 capbeam & 20 & 8.4 & 0.05 & -0.003 & 0.42 & -0.001 \\
\hline 11 & G8 girder (left) & 20 & 10.1 & 0.05 & 0.003 & 0.51 & 0.030 \\
\hline 12 & A17 abutment & 25 & 10.3 & 0.05 & 0.010 & 0.52 & 0.103 \\
\hline 13 & G3 girder (right) $M$ & 20 & 10.9 & 0.05 & 0.017 & 0.55 & 0.185 \\
\hline 14 & G15 girder (right) & 20 & 11.3 & 0.05 & 0.025 & 0.57 & 0.283 \\
\hline 15 & G4 girder (left) M & 20 & 13.0 & 0.05 & 0.030 & 0.65 & 0.390 \\
\hline 16 & C5 pier (back) & 25 & 22.6 & 0.05 & 0.041 & 1.13 & 0.927 \\
\hline 17 & C3 deck & 30 & 52.6 & 0.05 & 0.049 & 2.63 & 2.577 \\
\hline 18 & $\mathrm{~S} 12$ deck & 30 & 59.4 & 0.05 & 0.060 & 2.97 & 3.564 \\
\hline 19 & S10 deck & 30 & 63.8 & 0.05 & 0.076 & 3.19 & 4.849 \\
\hline $\mathrm{n}=20$ & S8 deck & 30 & 79.1 & 0.05 & 0.113 & 3.96 & 8.938 \\
\hline
\end{tabular}

*: The actual service life of the structural members, $t_{0}=20$ years; the normal distribution of cover thickness, $\mathrm{N}(24,3.485)$; $a_{i}=\left[\frac{1}{n} \sum_{i=1}^{n} x_{i}\right] /\left[\sum_{i=1}^{n} x_{i}\right]=0.05 ; \quad \mu_{x}=\sum_{i=1}^{n} a_{i} x_{i}=19.32 ; \sigma_{x}=\sum_{i=1}^{n} b_{i} x_{i}=20.432 ; \quad \beta=\frac{\mu_{d}-\mu_{x}}{\sqrt{\sigma_{d}^{2}+\sigma_{x}^{2}}}=\frac{24-19.32}{\sqrt{(3.485)^{2}+(20.432)^{2}}}=$ $\frac{4.68}{20.727}=0.23 ; P_{f}=\Phi(-\beta)=\Phi(-0.23)=0.01287$ 
Table 4. Unbiased estimation of concrete carbonation depth for the Way-shuang rivulet bridge in Taipei*

\begin{tabular}{cccccccc}
\hline $\begin{array}{c}\text { Order } \\
i\end{array}$ & $\begin{array}{c}\text { Member } \\
\text { Classification }\end{array}$ & $\begin{array}{c}\text { Cover } \\
\text { Thickness } \\
d(\mathrm{~mm})\end{array}$ & $\begin{array}{c}\text { Carbonation } \\
\text { Depth } \\
x_{i}(\mathrm{~mm})\end{array}$ & $a_{i}$ & $b_{i}$ & $a_{i} x_{i}$ & $b_{i} x_{i}$ \\
\hline 1 & A2 abutment (middle) & 25 & 0.0 & 0.17 & -0.318 & 0.00 & 0.00 \\
2 & S2-1 deck & 20 & 0.0 & 0.17 & -0.139 & 0.00 & 0.00 \\
3 & G-1-4 girder & 20 & 1.5 & 0.17 & -0.043 & 0.26 & -0.065 \\
4 & G2-5 girder & 20 & 6.5 & 0.17 & 0.043 & 1.11 & 0.280 \\
5 & A2 abutment (middle) & 25 & 18.0 & 0.17 & 0.139 & 3.06 & 2.502 \\
$\mathrm{n}=6$ & P15 pier (back) & 35 & 19.3 & 0.17 & 0.318 & 3.28 & 6.137 \\
\hline
\end{tabular}

*: The actual service life of the structural members, $t_{0}=26$ years; the normal distribution of cover thickness, $\mathrm{N}(24.17,5.68)$; $a_{i}=\left[\frac{1}{n} \sum_{i=1}^{n} x_{i}\right] /\left[\sum_{i=1}^{n} x_{i}\right]=0.17 ; \quad \mu_{x}=\sum_{i=1}^{n} a_{i} x_{i}=7.71 ; \sigma_{x}=\sum_{i=1}^{n} b_{i} x_{i}=8.854 ; \quad \beta=\frac{\mu_{d}-\mu_{x}}{\sqrt{\sigma_{d}^{2}+\sigma_{x}^{2}}}=\frac{24.17-7.71}{\sqrt{(5.68)^{2}+(8.854)^{2}}}=\frac{16.46}{10.519}$ $=1.56 ; P_{f}=\Phi(-\beta)=\Phi(-1.56)=0.05938$

Table 5. Unbiased estimation of concrete carbonation depth for the Her-pyng west road viaduct in Taipei*

\begin{tabular}{cccccccc}
\hline $\begin{array}{c}\text { Order } \\
i\end{array}$ & $\begin{array}{c}\text { Member } \\
\text { Classification }\end{array}$ & $\begin{array}{c}\text { Cover } \\
\text { Thickness } \\
d(\mathrm{~mm})\end{array}$ & $\begin{array}{c}\text { Carbonation } \\
\text { Depth } \\
x_{i}(\mathrm{~mm})\end{array}$ & $a_{i}$ & $b_{i}$ & $a_{i} x_{i}$ & $b_{i} x_{i}$ \\
\hline 1 & P5 capbeam (middle) & 20 & 0.0 & 0.08 & -0.175 & 0.000 & 0.000 \\
2 & P3 capbeam (middle) & 20 & 0.0 & 0.08 & -0.106 & 0.000 & 0.000 \\
3 & S6-3 deck & 20 & 1.6 & 0.08 & -0.075 & 0.128 & -0.120 \\
4 & P6 pier (right, back) & 35 & 10.5 & 0.08 & -0.051 & 0.840 & -0.536 \\
5 & G3 girder (left) & 20 & 11 & 0.08 & -0.029 & 0.880 & -0.319 \\
6 & G2 girder (right) & 20 & 11.9 & 0.08 & -0.010 & 0.952 & -0.119 \\
7 & G7 girder (left) & 35 & 12.9 & 0.08 & 0.010 & 1.032 & 0.129 \\
8 & P2 bridge pier (middle, back) & 35 & 13 & 0.08 & 0.029 & 1.040 & 0.377 \\
9 & P2 capbeam(middle) & 20 & 17.6 & 0.08 & 0.051 & 1.408 & 0.898 \\
10 & G9-3 girder & 20 & 18.3 & 0.08 & 0.075 & 1.464 & 1.373 \\
11 & P5 capbeam(middle) & 20 & 18.4 & 0.08 & 0.106 & 1.472 & 1.950 \\
$\mathrm{n}=12$ & S-3-2 deck & 20 & 38.3 & 0.08 & 0.175 & 3.064 & 6.703 \\
\hline
\end{tabular}

*: The actual service life of the structural members, $t_{0}=18$ years; the normal distribution of cover thickness, $\mathrm{N}(23.75,5.34)$; $a_{i}=\left[\frac{1}{n} \sum_{i=1}^{n} x_{i}\right] /\left[\sum_{i=1}^{n} x_{i}\right]=0.05 ; \mu_{x}=\sum_{i=1}^{n} a_{i} x_{i}=12.28 ; \sigma_{x}=\sum_{i=1}^{n} b_{i} x_{i}=10.336 ; \beta=\frac{\mu_{d}-\mu_{x}}{\sqrt{\sigma_{d}^{2}+\sigma_{x}^{2}}}=\frac{23.75-12.28}{\sqrt{(5.34)^{2}+(10.336)^{2}}}=\frac{11.47}{11.634}$ $=0.99 ; P_{f}=\Phi(-\beta)=\Phi(-0.99)=0.1611$

Table 6. Unbiased estimation of concrete carbonation depth for the Jzyh-chyang bridge in Taipei*

\begin{tabular}{cccccccc}
\hline $\begin{array}{c}\text { Order } \\
i\end{array}$ & $\begin{array}{c}\text { Member } \\
\text { Classification }\end{array}$ & $\begin{array}{c}\text { Cover } \\
\text { Thickness } \\
d(\mathrm{~mm})\end{array}$ & $\begin{array}{c}\text { Carbonation } \\
\text { Depth } \\
x_{i}(\mathrm{~mm})\end{array}$ & $a_{i}$ & $b_{i}$ & $a_{i} x_{i}$ & $b_{i} x_{i}$ \\
\hline 1 & A4 abutment & 20 & 5.4 & 0.13 & -0.248 & 0.702 & -1.339 \\
2 & S4 deck & 25 & 5.9 & 0.13 & -0.129 & 0.767 & -0.761 \\
3 & S2 deck & 25 & 6.5 & 0.13 & -0.071 & 0.845 & -0.462 \\
4 & P2 pier (left) & 35 & 6.6 & 0.13 & -0.023 & 0.858 & -0.152 \\
5 & A2 abutment & 20 & 14.0 & 0.13 & 0.023 & 1.820 & 0.322 \\
6 & P1 pier (left) & 35 & 16.9 & 0.13 & 0.071 & 2.197 & 1.200 \\
7 & S4 diaphram & 30 & 46.6 & 0.13 & 0.129 & 6.058 & 6.011 \\
$\mathrm{n}=8$ & S2 diaphram-1 & 30 & 52.6 & 0.13 & 0.248 & 6.838 & 13.045 \\
\hline
\end{tabular}

*: The actual service life of the structural members, $t_{0}=26$ years; the normal distribution of cover thickness, $\mathrm{N}(27.5,6.125)$; $a_{i}=\left[\frac{1}{n} \sum_{i=1}^{n} x_{i}\right] /\left[\sum_{i=1}^{n} x_{i}\right]=0.13 ; \mu_{x}=\sum_{i=1}^{n} a_{i} x_{i}=20.09 ; \sigma_{x}=\sum_{i=1}^{n} b_{i} x_{i}=17.864 ; \beta=\frac{\mu_{d}-\mu_{x}}{\sqrt{\sigma_{d}^{2}+\sigma_{x}^{2}}}=\frac{27.5-20.09}{\sqrt{(6.125)^{2}+(17.864)^{2}}}=\frac{7.41}{18.885}$ $=0.39 ; P_{f}=\Phi(-\beta)=\Phi(-0.39)=0.3483$ 
Table 7. Unbiased estimation of concrete carbonation depth for the Ay-gwo west road viaduct in Taipei*

\begin{tabular}{|c|c|c|c|c|c|c|c|}
\hline $\begin{array}{l}\text { Order } \\
\quad i\end{array}$ & $\begin{array}{c}\text { Member } \\
\text { Classification }\end{array}$ & $\begin{array}{c}\text { Cover } \\
\text { Thickness } \\
d(\mathrm{~mm})\end{array}$ & $\begin{array}{c}\text { Carbonation } \\
\text { Depth } \\
x_{i}(\mathrm{~mm})\end{array}$ & $a_{i}$ & $b_{i}$ & $a_{i} x_{i}$ & $b_{i} x_{i}$ \\
\hline 1 & deck 1 & 25 & 0.0 & 0.06 & -0.124 & 0.000 & 0.000 \\
\hline 2 & deck 2 & 25 & 0.0 & 0.06 & -0.082 & 0.000 & 0.000 \\
\hline 3 & deck 3 & 25 & 0.0 & 0.06 & -0.065 & 0.000 & 0.000 \\
\hline 4 & deck 4 & 25 & 0.0 & 0.06 & -0.050 & 0.000 & 0.000 \\
\hline 5 & S9A girder & 20 & 3.0 & 0.06 & -0.041 & 0.180 & -0.123 \\
\hline 6 & S1-3 girder & 20 & 11.3 & 0.06 & -0.030 & 0.678 & -0.339 \\
\hline 7 & ramp B & 30 & 11.5 & 0.06 & -0.020 & 0.690 & -0.230 \\
\hline 8 & $\mathrm{~S} 12$ girder & 20 & 11.8 & 0.06 & -0.014 & 0.708 & -0.165 \\
\hline 9 & S3-3 girder & 20 & 12.9 & 0.06 & -0.004 & 0.774 & -0.052 \\
\hline 10 & P3 pier(right) & 20 & 13.0 & 0.06 & 0.004 & 0.780 & 0.052 \\
\hline 11 & P7 pier(right) & 30 & 15.9 & 0.06 & 0.014 & 0.954 & 0.223 \\
\hline 12 & $\mathrm{P} 2$ capbeam & 20 & 18.6 & 0.06 & 0.020 & 1.116 & 0.372 \\
\hline 13 & P11 pier & 30 & 18.9 & 0.06 & 0.030 & 1.134 & 0.567 \\
\hline 14 & S5-3 girder & 20 & 21.3 & 0.06 & 0.041 & 1.278 & 0.873 \\
\hline 15 & guide passage A(South) & 30 & 22.4 & 0.06 & 0.050 & 1.344 & 1.120 \\
\hline 16 & Abutment A & 25 & 23.6 & 0.06 & 0.065 & 1.416 & 1.534 \\
\hline 17 & Abutment $\mathrm{C}$ & 25 & 26.6 & 0.06 & 0.082 & 1.596 & 2.181 \\
\hline $\mathrm{n}=18$ & P7 pier(middle) & 30 & 32.4 & 0.06 & 0.124 & 1.994 & 4.018 \\
\hline
\end{tabular}

*: The actual service life of the structural members, $t_{0}=15$ years; the normal distribution of cover thickness, $\mathrm{N}(24.44,3.87)$; $a_{i}=\left[\frac{1}{n} \sum_{i=1}^{n} x_{i}\right] /\left[\sum_{i=1}^{n} x_{i}\right]=0.06 ; \mu_{x}=\sum_{i=1}^{n} a_{i} x_{i}=14.492 ; \sigma_{x}=\sum_{i=1}^{n} b_{i} x_{i}=10.031 ; \beta=\frac{\mu_{d}-\mu_{x}}{\sqrt{\sigma_{d}^{2}+\sigma_{x}^{2}}}=\frac{24.43-14.492}{\sqrt{(3.87)^{2}+(10.031)^{2}}}=\frac{9.94}{10.75}$ $=0.92 ; P_{f}=\Phi(-\beta)=\Phi(-0.92)=0.1814$

Table 8. Unbiased estimation of concrete carbonation depth for the Hwan-nan viaductin Taipei*

\begin{tabular}{|c|c|c|c|c|c|c|c|}
\hline $\begin{array}{l}\text { Order } \\
\quad i\end{array}$ & $\begin{array}{c}\text { Member } \\
\text { Classification }\end{array}$ & $\begin{array}{c}\text { Cover } \\
\text { Thickness } \\
d(\mathrm{~mm})\end{array}$ & $\begin{array}{c}\text { Carbonation } \\
\text { Depth } \\
x_{i}(\mathrm{~mm})\end{array}$ & $a_{i}$ & $b_{i}$ & $a_{i} x_{i}$ & $b_{i} x_{i}$ \\
\hline 1 & P80 pier & 30 & 0.0 & 0.05 & -0.113 & 0.000 & 0.000 \\
\hline 2 & $\mathrm{R} 1$ papapet & 30 & 0.0 & 0.05 & -0.076 & 0.000 & 0.000 \\
\hline 3 & P58 capbeam & 30 & 0.0 & 0.05 & -0.061 & 0.000 & 0.000 \\
\hline 4 & $\mathrm{R} 9$ ramp (east) & 30 & 0.0 & 0.05 & -0.049 & 0.000 & 0.000 \\
\hline 5 & S50A deck & 30 & 0.0 & 0.05 & -0.041 & 0.000 & 0.000 \\
\hline 6 & S80 deck & 30 & 0.0 & 0.05 & -0.032 & 0.000 & 0.000 \\
\hline 7 & $\mathrm{~S} 1$ girder & 20 & 4.5 & 0.05 & -0.025 & 0.225 & -0.113 \\
\hline 8 & P44 capbeam & 20 & 6.3 & 0.05 & -0.017 & 0.315 & -0.107 \\
\hline 9 & P35 capbeam & 20 & 7.5 & 0.05 & -0.010 & 0.375 & -0.075 \\
\hline 10 & S67 capbeam & 20 & 8.5 & 0.05 & -0.003 & 0.425 & -0.026 \\
\hline 11 & S50A girder (left) & 20 & 8.5 & 0.05 & 0.003 & 0.425 & 0.026 \\
\hline 12 & S45B parapet & 20 & 13.5 & 0.05 & 0.010 & 0.675 & 0.135 \\
\hline 13 & $\mathrm{P} 45 \mathrm{~B}$ pier & 30 & 14.0 & 0.05 & 0.017 & 0.700 & 0.238 \\
\hline 14 & P58 pier & 30 & 14.3 & 0.05 & 0.025 & 0.715 & 0.358 \\
\hline 15 & P44 capbeam & 20 & 14.5 & 0.05 & 0.030 & 0.725 & 0.435 \\
\hline 16 & P1 capbeam & 20 & 15.5 & 0.05 & 0.041 & 0.755 & 0.636 \\
\hline 17 & P32 capbeam & 30 & 20.0 & 0.05 & 0.049 & 1.000 & 0.980 \\
\hline 18 & S53B parapet & 30 & 22.8 & 0.05 & 0.060 & 1.140 & 1.368 \\
\hline 19 & P69 capbeam & 30 & 25.1 & 0.05 & 0.076 & 1.255 & 1.908 \\
\hline $\mathrm{n}=20$ & P80 capbeam & 30 & 32.3 & 0.05 & 0.113 & 1.615 & 3.650 \\
\hline
\end{tabular}

*: The actual service life of the structural members, $t_{0}=24$ years; the normal distribution of cover thickness, $\mathrm{N}(26,4.05)$; $a_{i}=\left[\frac{1}{n} \sum_{i=1}^{n} x_{i}\right] /\left[\sum_{i=1}^{n} x_{i}\right]=0.05 ; \quad \mu_{x}=\sum_{i=1}^{n} a_{i} x_{i}=10.345 ; \sigma_{x}=\sum_{i=1}^{n} b_{i} x_{i}=9.413 ; \quad \beta=\frac{\mu_{d}-\mu_{x}}{\sqrt{\sigma_{d}^{2}+\sigma_{x}^{2}}}=\frac{26-10.345}{\sqrt{(4.05)^{2}+(9.413)^{2}}}=\frac{15.655}{10.274}$
$=1.53 ; P_{f}=\Phi(-\beta)=\Phi(-1.53)=0.06426$ 
Table 9. Unbiased estimation of concrete carbonation depth for the Daw-nan bridge in Taipei*

\begin{tabular}{cccccccc}
\hline $\begin{array}{c}\text { Order } \\
i\end{array}$ & $\begin{array}{c}\text { Member } \\
\text { Classification }\end{array}$ & $\begin{array}{c}\text { Cover } \\
\text { Thickness } \\
d(\mathrm{~mm})\end{array}$ & $\begin{array}{c}\text { Carbonation } \\
\text { Depth } \\
x_{i}(\mathrm{~mm})\end{array}$ & $a_{i}$ & $b_{i}$ & $a_{i} x_{i}$ & $b_{i} x_{i}$ \\
\hline 1 & G1-1 girder & 20 & 0.0 & 0.1 & -0.204 & 0.000 & 0.000 \\
2 & S2-2 deck & 20 & 1.3 & 0.1 & -0.117 & 0.130 & -0.152 \\
3 & G3-7 girder & 20 & 2.3 & 0.1 & -0.076 & 0.230 & -0.175 \\
4 & P2 pier (back) & 35 & 4.8 & 0.1 & -0.044 & 0.480 & -0.211 \\
5 & P2 capbeam(back $)$ & 20 & 5.0 & 0.1 & -0.014 & 0.500 & -0.070 \\
6 & A1 abutment & 25 & 6.0 & 0.1 & 0.014 & 0.600 & 0.084 \\
7 & G3-2 girder & 20 & 13.6 & 0.1 & 0.044 & 1.360 & 0.598 \\
8 & G1-6 girder & 20 & 14.1 & 0.1 & 0.076 & 1.410 & 1.072 \\
9 & P1 pier & 35 & 25.8 & 0.1 & 0.117 & 2.580 & 3.019 \\
$\mathrm{n}=10$ & A2 abutment & 25 & 34.1 & 0.1 & 0.204 & 3.410 & 6.956 \\
\hline
\end{tabular}

*: The actual service life of the structural members, $t_{0}=14$ years; the normal distribution of cover thickness, $\mathrm{N}(24,5.415)$; $a_{i}=\left[\frac{1}{n} \sum_{i=1}^{n} x_{i}\right] /\left[\sum_{i=1}^{n} x_{i}\right]=0.1 ; \mu_{x}=\sum_{i=1}^{n} a_{i} x_{i}=10.70 ; \sigma_{x}=\sum_{i=1}^{n} b_{i} x_{i}=11.121 ; \beta=\frac{\mu_{d}-\mu_{x}}{\sqrt{\sigma_{d}^{2}+\sigma_{x}^{2}}}=\frac{24-10.70}{\sqrt{(5.415)^{2}+(11.121)^{2}}}=\frac{13.3}{12.369}$ $=1.08 ; P_{f}=\Phi(-\beta)=\Phi(-1.08)=0.1401$

Table 10. Unbiased estimation of concrete carbonation depth for the Shi-yuan bridge in Taipei*

\begin{tabular}{cccccccc}
\hline $\begin{array}{c}\text { Order } \\
i\end{array}$ & Classification & $\begin{array}{c}\text { Cover } \\
\text { Thickness } \\
d(\mathrm{~mm})\end{array}$ & $\begin{array}{c}\text { Carbonation } \\
\text { Depth } \\
x_{i}(\mathrm{~mm})\end{array}$ & $a_{i}$ & $b_{i}$ & $a_{i} x_{i}$ & $b_{i} x_{i}$ \\
\hline 1 & G13-1 girder & 25 & 0.0 & 0.05 & -0.113 & 0.000 & 0.000 \\
2 & S9 deck & 25 & 0.0 & 0.05 & -0.076 & 0.000 & 0.000 \\
3 & S10 deck & 25 & 0.0 & 0.05 & -0.061 & 0.000 & 0.000 \\
4 & P3 capbeam & 20 & 4.8 & 0.05 & -0.049 & 0.240 & -0.235 \\
5 & P14 capbeam & 20 & 5.3 & 0.05 & -0.041 & 0.265 & -0.217 \\
6 & G17-1 girder & 25 & 5.9 & 0.05 & -0.032 & 0.295 & -0.189 \\
7 & G7-1 girder & 25 & 9.1 & 0.05 & -0.025 & 0.455 & -0.228 \\
8 & G4-1 girder & 25 & 10.3 & 0.05 & -0.017 & 0.515 & -0.179 \\
9 & G6-1 girder & 25 & 10.5 & 0.05 & -0.010 & 0.525 & -0.105 \\
10 & G10-1 girder & 25 & 11.3 & 0.05 & -0.003 & 0.565 & -0.034 \\
11 & P8 capbeam (back) & 25 & 14.5 & 0.05 & 0.003 & 0.725 & 0.044 \\
12 & P17 pier (right) & 30 & 15.9 & 0.05 & 0.010 & 0.795 & 0.159 \\
13 & GR-2 girder & 25 & 16.4 & 0.05 & 0.017 & 0.820 & 0.279 \\
14 & P4 capbeam & 20 & 16.5 & 0.05 & 0.025 & 0.825 & 0.413 \\
15 & A18 abutment & 25 & 20.5 & 0.05 & 0.030 & 1.025 & 0.615 \\
16 & P96 capbeam (back) & 25 & 21.8 & 0.05 & 0.041 & 1.090 & 0.894 \\
17 & P17 capbeam (back) & 25 & 25.4 & 0.05 & 0.049 & 1.270 \\
18 & P13 capbeam & 20 & 34.3 & 0.05 & 0.060 & 1.715 & 1.245 \\
19 & P7 capbeam (back) & 25 & 35.4 & 0.05 & 0.076 & 1.770 & 2.058 \\
$\mathrm{n}=20$ & DR-4 diaphram & 25 & 37.5 & 0.05 & 0.113 & 1.875 & 4.238 \\
\hline
\end{tabular}

*: The actual service life of the structural members, $t_{0}=24$ years; the normal distribution of cover thickness, $\mathrm{N}(24.25,1.985)$; $a_{i}=\left[\frac{1}{n} \sum_{i=1}^{n} x_{i}\right] /\left[\sum_{i=1}^{n} x_{i}\right]=0.05 ; \mu_{x}=\sum_{i=1}^{n} a_{i} x_{i}=14.775 ; \sigma_{x}=\sum_{i=1}^{n} b_{i} x_{i}=10.553 ; \beta=\frac{\mu_{d}-\mu_{x}}{\sqrt{\sigma_{d}^{2}+\sigma_{x}^{2}}}=\frac{24-14.775}{\sqrt{(1.985)^{2}+(10.553)^{2}}}=\frac{9.475}{10.738}$ $=0.88 ; P_{f}=\Phi(-\beta)=\Phi(-0.88)=0.1894$

\section{RESULTS AND DISCUSSION}

The ten bridges in Taipei were reinforced concrete structures. The linearly unbiased parameter estimation method was used to analyze these bridges. The mean value, $\mu_{x}$, and standard deviation, $\sigma_{x}$, of the carbonation 
Table 11. Unbiased estimation of concrete carbonation depth for the Chung-san bridge in Taipei*

\begin{tabular}{cccccccc}
\hline $\begin{array}{c}\text { Order } \\
i\end{array}$ & $\begin{array}{c}\text { Member } \\
\text { Classification }\end{array}$ & $\begin{array}{c}\text { Cover } \\
\text { Thickness } \\
d(\mathrm{~mm})\end{array}$ & $\begin{array}{c}\text { Carbonation } \\
\text { Depth } \\
x_{i}(\mathrm{~mm})\end{array}$ & $a_{i}$ & $b_{i}$ & $a_{i} x_{i}$ & $b_{i} x_{i}$ \\
\hline 1 & Vaulted rib & 30 & 10.0 & 0.17 & -0.318 & 1.70 & -3.180 \\
2 & Drainage system & 24 & 10.0 & 0.17 & -0.139 & 1.70 & -1.390 \\
3 & Pier & 37 & 13.0 & 0.17 & -0.043 & 2.21 & -0.559 \\
4 & Extended for pavement & 20 & 15.0 & 0.17 & 0.043 & 2.55 & 0.645 \\
& cantilever beam & & & & & & \\
5 & Deck & 27 & 22.0 & 0.17 & 0.139 & 3.74 & 3.058 \\
$\mathrm{n}=6$ & Supported plate & 52 & 23.0 & 0.17 & 0.318 & 3.91 & 7.314 \\
\hline
\end{tabular}

*: The actual service life of the structural members, $t_{0}=26$ years; the normal distribution of cover thickness, $\mathrm{N}(31.67,12.112)$;

$$
\begin{aligned}
& a_{i}=\left[\frac{1}{n} \sum_{i=1}^{n} x_{i}\right] /\left[\sum_{i=1}^{n} x_{i}\right]=0.17 ; \quad \mu_{x}=\sum_{i=1}^{n} a_{i} x_{i}=15.81 ; \sigma_{x}=\sum_{i=1}^{n} b_{i} x_{i}=5.888 ; \beta=\frac{\mu_{d}-\mu_{x}}{\sqrt{\sigma_{d}^{2}+\sigma_{x}^{2}}}=\frac{31.67-15.81}{\sqrt{(12.112)^{2}+(5.888)^{2}}}=\frac{15.86}{13.467} \\
& =1.18 ;{ }_{f}=\Phi(-\beta)=\Phi(-1.18)=0.119
\end{aligned}
$$

Table 12. Reliability index and failure probability of concrete bridges in Taipei

\begin{tabular}{ccccc}
\hline $\begin{array}{c}\text { Order } \\
i\end{array}$ & Bridge name & $\begin{array}{c}t_{0}{ }^{*} \\
\text { (years) }\end{array}$ & $\begin{array}{c}\text { Reliability index } \\
\beta\end{array}$ & $\begin{array}{c}\text { Failure probability } \\
P_{f}\end{array}$ \\
\hline 1 & the Huey-tong bridge & 49 & 2.03 & $2.118 \times 10^{-2}$ \\
2 & the Beei-men viaduct & 20 & 0.23 & $1.287 \times 10^{-2}$ \\
3 & the Way-shuang rivulet bridge & 26 & 1.56 & $5.938 \times 10^{-2}$ \\
4 & the Her-pyng west road viaduct & 18 & 0.99 & $1.611 \times 10^{-1}$ \\
5 & The Jzyh-chyang bridge & 26 & 0.39 & $3.483 \times 10^{-1}$ \\
6 & the Ay-gwo west road viaduct & 15 & 0.92 & $1.814 \times 10^{-1}$ \\
7 & the Hwan-nan viaduct & 24 & 1.53 & $6.426 \times 10^{-2}$ \\
8 & the Daw-nan bridge & 14 & 1.08 & $1.401 \times 10^{-1}$ \\
9 & the Shi-yuan bridge & 24 & 0.88 & $1.894 \times 10^{-1}$ \\
$\mathrm{n}=10$ & the Chung-san bridge & 63 & 1.18 & $1.190 \times 10^{-1}$ \\
\hline
\end{tabular}

*: The actual service life of concrete bridge

depth of the concrete can be estimated using Eqs. (23) and (24). The coefficients $b_{i}$ in Eqs. (24) can be discovered from Table 1 . The mean value, $\mu_{d}$, and standard deviation, $\sigma_{d}$, of the cover thickness of concrete were calculated using the normal distribution method. These results are shown in Table 2 to 11 . The JC method was also adopted to predict the reliability index. This means that the substitution of $\mu_{x}, \sigma_{x}, \mu_{d}, \sigma_{d}$ into Eq. (32) leads to $\beta$. The reliability index, $\beta$, and corresponding failure probability, $P_{f}$, of each bridge in Taipei are listed in Table 12. It was found that both the Beei-men viaduct ( $\beta=0.23)$ and the Jzyh-chyang bridge $(\beta=0.39)$ require extensive repairs. Both the Ay-gwo west road viaduct $(\beta=0.92)$ and the Shi-yuan bridge $(\beta=0.88)$ require only limited repairs. The other bridges $(\beta=1 \sim 2.0)$ are safe and serviceable. It is worthwhile to point out that the old Chung-san bridge ( $\beta=1.18$ ) is the oldest, but is very sound. The major factor is that the old Chung-san bridge has enough concrete cover to retard corrosion. It is also worthwhile to express that the old Chung-san bridge was designed and constructed by Japanese when Taiwan was a Japanese colony.

The model for predicting the required extent of repair and failure probability in this paper is only based on carbonation depth and concrete cover thickness. This appears to be an oversimplified approach to the complex phenomenon of corrosion of steel in concrete. It is in fact that many factors must be considered to effectively assess the extent of corrosion damage, remaining service life, need for repairs and risk of failure for a structure. This paper does not address issues such as the effect of chlorides, concrete cracking, concrete type and mix proportions, cement chemistry, observed corrosion damage (i. e., cracking, spalling, staining), measured corrosion rates, half-cell potentials, the design details and configuration of the bridge, and the exposure conditions for the bridge. All of these factors can actually play a significant role in corrosion 
of metals in concrete structure and the need for repairs and failure probability. If this paper considered these issues and dismissed them in the research, this should be explained fully to justify highly simplified approach. If these issues have been overlooked, the validity and usefulness of the method presented in this paper may be questionable. It would be a great disservice to imply that the condition of a bridge and the need for repairs was based solely on the difference between the depth of carbonation and the concrete cover thickness. However, if this paper considered all these issues, this would not be possible. The aim of this paper provides a prediction model of the carbonation contamination of concrete bridge. Although the proposed model considered carbonation depth and cover thickness of concrete, the predicted results are good agreement with actual situation. It is obvious that the propose model in this paper is very useful.

\section{CONCLUSIONS}

The linearly unbiased estimation method associated with the JC method to evaluate the carbonation contamination of concrete bridges in the Taipei has been described. The results of this study show that both the Beei-men viaduct $(\beta=0.23)$ and the Jzyh-chyang bridge $(\beta=0.39)$ require extensive repairs. Both the Ay-gwo west road viaduct $(\beta=0.92)$ and the Shi-yuan bridge $(\beta=0.88)$ require limited repairs. The other bridges $(\beta=1 \sim 2.0)$ are safe and serviceable. Because the old Chung-san bridge has enough concrete cover, this bridge, even though it is the oldest among ten bridges, it is very sound.

Above all, the concrete cover thickness is the most important factor which determines the service life and durability of a bridge. Insufficient cover thickness is the decisive cause of the early and heavy degradation of reinforced concrete structures.

Measures to improve durability, such as maintaining a low water-cement ratio in the concrete mix, lessening the concentration of carbon dioxide gas are effective only when the cover thickness is sufficient. In order to make reinforced concrete structures durable, it is most important to avoid having an insufficient cover thickness.

Moreover, how many data points needed to use this proposed model effectively is necessary studied in advance. The range of reliability index required extensive repair, relatively light repair, safe and serviceable is also needed recommendations depended on more advanced investigation.

\section{REFERENCES}

1. Freudenthal, A., "Safety and probability of Structural
Failure," Transactions, ASCE, Vol. 121, pp. 1337 (1956).

2. Cornell, C. A., "Structural Safety Specification Based on Second-Moment Reliability Analysis," Final Report, Symposium on Concepts of Safety of Structures and Methods of Design, London, England, 1969, International Association for Bridges and Structural Engineering, Zurich, pp. 235-246 (1969).

3. Lind, N. C., "Deterministic Formats for the Probabilities Design of Structures," An Introduction to Structural Optimization, Cohn, M. Z., ed., SM Study No. 1, University of Water-loo, Water-loo, Ontario, pp. 121-142 (1969).

4. Ravindra, M. K., Heaney, A C. and Lind, N. C. "Probabilistic Evaluation of Safety Factors," Final Report, Symposium on Concepts of Safety of Structures and Methods of Design, London, England, 1969, International Association for Bridge and Structural Engineering, Zurich, Switzerland, pp. 35-46 (1969).

5. Ang, A. H.-S. and Amin, M., "Safety Factors and Probability in Structural Design," Journal of Structural Division, ASCE, Vol. 86, No. ST7, pp. 1389-1405 (1969).

6. Lind, N. C., "Consistent Partial Safety Factors," Journal of the Structural Division," ASCE, Vol. 97, No. ST6, pp. 1651-1669 (1971).

7. Paloheimo, E. and Hannus, M., "Structural Design Based on Weighted Fractiles," Journal of the Structural Division, ASCE, Vol. 100, No. ST7, pp. 1367-1378 (1974).

8. Stewart, M. G. and Rosowsky, D. V., "Structural Safety and Serviceability of Concrete Bridge Subject to Corrosion," Journal of Infrastructure Systems, Vol. 4, No. 4, pp. 146-155 (1998a).

9. Stewart, M. G. and Rosowsky, D. V., "Time-dependent Reliability of Deteriorating Reinforced Concrete Bridge Decks," Structural Safety, Vol. 20, pp. 91-109 (1998b).

10. ASTM Standard, "Standard Test Method for Compressive Strength of Cylindrical Concrete Specimens," C3986, pp. 20-24 (1990).

11. Dhir, R. K., Hewlett, P. C., and Chan, Y. N., "Nearsurface Characteristics of Concrete: Prediction of Carbonation Resistance," Magazine of Concrete Research, Vol. 41, No. 148, pp. 137-143 (1989).

12. Papadakis, V. G., Vayenas, C. G., and Fardis, M. N., "Experimental Investigation and Mathematical Model of the Concrete Carbonation Problem," Chemical Engineering Science, Vol. 46, No. 5/6, pp. 1333-1338 (1991).

13. Loo, Y. H., Chin, M. S., Tam, C. T., and Ong, K. C. G., "A Carbonation Prediction Model for Accelerated Carbonation Testing of Concrete," Magazine of Concrete Research, Vol. 46, No. 168, pp. 191-200 (1994).

14. Al-Khaiat, H. and Haque, M. N., "Carbonation of Some Coastal Concrete Structures in Kuwait," ACI Materials Journal, Vol. 94, No. 6, pp. 602-607 (1997). 


\title{
線性無偏結合JC方法評估台北市混 凝土橋樑的碳化損傷
}

\author{
梁 明 德
}

國立台灣海洋大學河海工程學系

趙國藩

大連理工大學土木工程學系

\section{廖 晏 聖}

國立台灣海洋大學河海工程學系

梁 智 信

國立台灣海洋大學材料工程研究所

\section{摘 要}

本文研究的主要目的是探討具有碳化損傷的既 有混凝土橋樑之耐久性評估，採用線性無偏評估法結 合由國際結構安全度聯合委員研發的JC法, 首先分別 預測混凝土橋樑之碳化深度和保護層厚度之常態分佈 的平均值和標準偏差, 進而計算混凝土橋樑的可靠性 指標 $\beta$ 及失效機率 $P$ 。因爲線性無偏評估法非常適合 分析僅有少數樣本的實際工程問題, 且未知參數可以 很方便和精確計算, 所以本文採用此法。爲驗正本文 建議方法的實用性, 應用台北市十座混凝土橋樑爲範 例, 分別計算各座橋樑之平均值、標準偏差、可靠性 指標及失效機率。研究結果表明北門高架橋 $\beta=0.23$ 及自強橋 $\beta=0.39$ 需要維修, 愛國西路高架橋 $\beta=$ 0.92 和西園橋 $\beta=0.88$ 需要小維修, 其餘橋樑 $\beta=1 \sim$ 2.0 可安全使用。 